Article

\title{
An Optical MEMS Acoustic Sensor Based on Grating Interferometer
}

\author{
Mengying Zhang ${ }^{1,2}$, Gaomi Wu ${ }^{1,3}$, Dipeng Ren ${ }^{1,3}$, Ran Gao ${ }^{1}$, Zhi-Mei Qi ${ }^{1,3, *}$ and \\ Xingdong Liang ${ }^{2}$ \\ 1 State Key Laboratory of Transducer Technology, Institute of Electronics, Chinese Academy of Sciences, \\ Beijing 100190, China; zhangmengying411@sina.com (M.Z.); gaomi_wu@126.com (G.W.); \\ rendipeng16@mails.ucas.ac.cn (D.R.); rgao@mail.ie.ac.cn (R.G.) \\ 2 Science and Technology on Microwave Imaging Laboratory, Institute of Electronics, Chinese Academy of \\ Sciences, Beijing 100190, China; xdliang@mail.ie.ac.cn \\ 3 School of Electronic, Electrical and Communication Engineering, University of Chinese Academy of \\ Sciences, Beijing 100049, China \\ * Correspondence: zhimei-qi@mail.ie.ac.cn; Tel.: +86-10-5888-7196
}

Received: 15 February 2019; Accepted: 25 March 2019; Published: 28 March 2019

\begin{abstract}
Acoustic detection is of great significance because of its wide applications. This paper reports a Micro-Electro-Mechanical System (MEMS) acoustic sensor based on grating interferometer. In the MEMS structure, a diaphragm and a micro-grating made up the interference cavity. A short-cavity structure was designed and fabricated to reduce the impact of temperature on the cavity length in order to improve its stability against environment temperature variations. Besides this, through holes were designed in the substrate of the grating to reduce the air damping of the short-cavity structure. A silicon diaphragm with a $16.919 \mu \mathrm{m}$ deep cavity and $2.4 \mu \mathrm{m}$ period grating were fabricated by an improved MEMS process. The fabricated sensor chip was packaged on a conditioning circuit with a laser diode and a photodetector for acoustic detection. The output voltage signal in response to an acoustic wave is of high quality. The sensitivity of the acoustic sensor is up to $-15.14 \mathrm{~dB}$ re $1 \mathrm{~V} / \mathrm{Pa} @ 1 \mathrm{kHz}$. The output signal of the high-stability acoustic sensor almost unchanged as the environment temperature ranged from $5{ }^{\circ} \mathrm{C}$ to $55^{\circ} \mathrm{C}$.
\end{abstract}

Keywords: MEMS; acoustic sensors; grating; interferometry; stability

\section{Introduction}

Acoustic detection is of great significance because of its wide applications to environmental monitoring, health monitoring, mechanical fault diagnosis, and building defect examination. Compared with the conventional acoustic sensors based on electric methods, such as capacitance sensors and piezoresistive sensors, the optical ones are immune to electromagnetic interference (EMI), capable of multiplexing, and able to achieve high sensitivity with small size. Many types of fiber-optic acoustic sensors, based on fiber Bragg gratings [1,2], intensity modulation [3], and interferometers, had been reported. Among them, the interferometric sensors, such as Fabry-Pérot interferometers [4-6], Mach-Zehnder interferometers [7-9], and Sagnac interferometers [10], have achieved high sensitivity and low minimum detectable pressure.

With the development of MEMS (Micro-Electro-Mechanical System) technology, optical acoustic sensors based on the MEMS structure have attracted much attention. First of all, the structures of the MEMS acoustic sensors are able to be designed flexibly for specific requirements or high performance. Vibration films with different microstructures have been developed, replacing the common uniform flat ones to improve the sensitivity and stability of sensors [11,12]. In addition, with high-precision 
MEMS technology, micro-sized designs of sensors are able to be well realized $[13,14]$. Compared with sensors which only use the MEMS component as a part of the whole assembled structure, those with an integrated MEMS structure based on a grating interferometer show enhanced stability because their interference cavity is stable and precisely controlled. Besides this, the performance of the sensor is improved by taking advantage of the diffraction characteristics of the grating [15]. As there are still electro components in the common systems of the sensors based on grating interferometers, they are opto-electronic sensors. Although the sensors are not immune to EMI, they still have the advantages of high sensitivity and small size. In addition to acoustic signals [16], sensors based on grating interferometers have also been applied to detecting position [17], displacement [18], and acceleration [19].

Sensitivity and stability are both important performance parameters of acoustic sensors for application. Low stability against environmental temperature variations is a serious problem for optical acoustic sensors, especially for the highly sensitive interferometric ones. Most of the methods which have been reported to solve the problem concern the laser source or the signal processing system [20,21] with additional complex operation, devices, and cost. Some other research improved the stability by altering the design of the interference cavity, such as by matching the materials [22,23] and optimizing the interference light field [24]. More effort is still needed to develop acoustic sensors with high sensitivity, high stability, and a simple system.

In this work, an optical MEMS acoustic sensor based on grating interferometer was designed and fabricated. The short-cavity structure was designed to improve its stability against environmental temperature variations. The sensor chip was packaged with the optical devices and a conditioning circuit for acoustic detection. Then, the response of the acoustic sensor to acoustic signals and temperature was tested.

\section{Materials and Methods}

\subsection{The acoustic sensor design}

The acoustic sensor reported in this work is shown in Figure 1. The MEMS sensor chip consists of two components: the diaphragm and the micro-grating. The vertical distance between the back surface of the diaphragm and the surface of the grating is the cavity length of the micro-grating interferometer, represented by $L$.

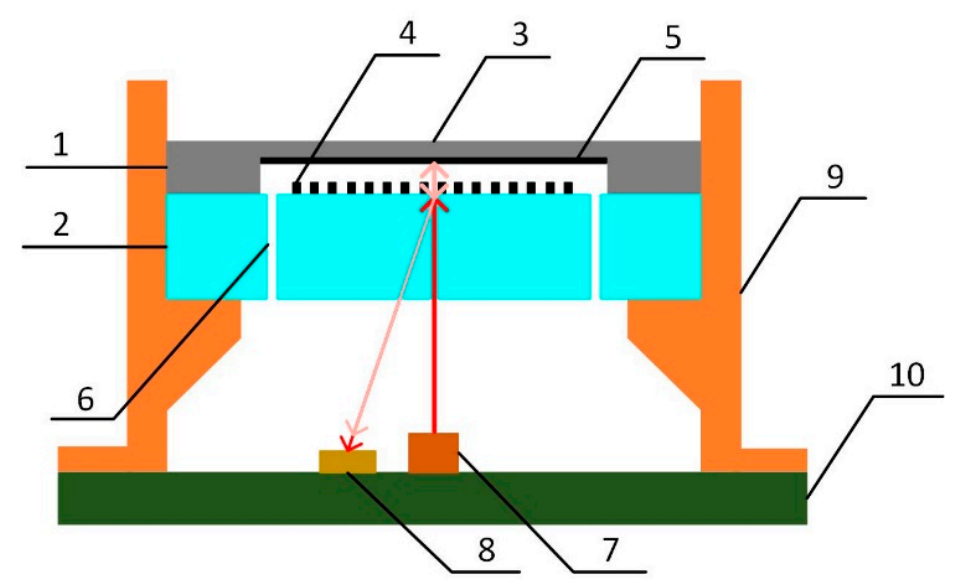

Figure 1. Schematic of the acoustic sensor. 1: Silicon substrate. 2: Glass substrate. 3: Diaphragm. 4: Grating. 5: Reflective layer. 6: Through hole. 7: Laser diode. 8: Photodetector. 9: Housing. 10: Printed circuit board.

A packaging structure was designed for the MEMS acoustic sensor chip. A laser diode with an integrated collimation structure was installed on the printed circuit board (PCB) to provide a $650 \mathrm{~nm}$ 
wavelength laser. It was placed vertically under the sensor chip and at the center. A photodetector matching with the laser was installed beside the laser diode at a specific distance. Both of the optical devices were connected with the circuit.

When the acoustic sensor was operated, coherent light from the laser diode was vertically incident on the micro-grating. One part of the light was diffracted and reflected back, while another part passed through the grating and was vertically incident on the diaphragm. Then, the back surface of the diaphragm reflected the light back to the grating, and the light was diffracted again. The two diffracted light beams of the same order were at the same angle, and they interfered with the optical path difference of $2 L$. The intensity of the interference light at the first diffraction order of the grating is shown in equation (1) [15]:

$$
I_{1}=\frac{4 I_{\text {in }}}{\pi^{2}} \sin ^{2}\left(\frac{\phi}{2}\right)=\frac{4 I_{\text {in }}}{\pi^{2}} \sin ^{2}\left(\frac{2 \pi L}{\lambda}\right)=\frac{2 I_{\text {in }}}{\pi^{2}}\left[1-\cos \left(\frac{4 \pi L}{\lambda}\right)\right]
$$

where $I_{\text {in }}$ is the intensity of the incident light, $\Phi$ is the relative phase difference between the two diffracted light beams, and $\lambda$ is the wavelength of the laser.

When acoustic pressure was loaded on the sensor, the diaphragm was deformed and the cavity length was changed. According to equation (1), the intensity of the interference light varied with the cavity length. Thus, the interference light was modulated by the acoustic wave. Then, it was detected by the photodetector, and the optical signal was processed by a conditioning circuit to output the voltage signal for acoustic detection.

In order to enhance the sensitivity of the acoustic sensor, its structure was optimized. The diaphragm was designed with $3 \mu \mathrm{m}$ thickness and $6 \mathrm{~mm}$ diameter. A reflective layer was added on the back surface of the diaphragm to enhance the reflection and improve the detection sensitivity. The micro-grating in the sensor decided the path of the light. Considering the structure of the sensor, a larger diffraction angle would separate the outgoing interference light well, with a shorter vertical distance between the grating and the photodetector. This reduced the diffusion of the outgoing light and avoided interference by light of other orders at the same time, which meant higher sensitivity and lower noise. According to the diffraction characteristic of the grating, with vertically incident light, the angles of the diffraction orders are decided by the grating period, and a smaller period means a larger angle. The designed grating period is $2.4 \mu \mathrm{m}$, and the angle of the first diffraction order is calculated as $15.714^{\circ}$.

In order to improve the stability of the acoustic sensor against environment temperature variations, a short-cavity structure was designed. For interferometric sensors, the main reason for the stability problem is that the cavity length varies with the temperature. The relationship between them is shown in equation (2):

$$
\mathrm{d} L=\alpha L_{0} \mathrm{~d} T
$$

where $\alpha$ is the thermal expansion coefficient of the cavity. According to the equation, the shorter the cavity length is, the weaker the temperature influence is. The designed cavity length was reduced to $17 \mu \mathrm{m}$. In addition, to reduce the air damping-which became serious because of the small volume of the short cavity - through holes were made in the glass substrate to connect the cavity and the atmosphere.

\subsection{The MEMS sensor chip fabrication}

The MEMS process of the acoustic sensor chip was developed and optimized for the short-cavity grating interferometer structure, as Figure 2 shows. The diaphragm component was fabricated on a silicon-on-insulator (SOI) wafer, and the micro-grating was made on a borosilicate glass wafer. 


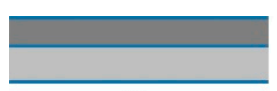

(a)

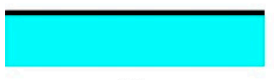

(I)

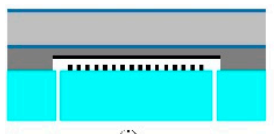

(i)

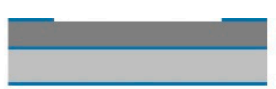

(b)

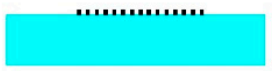

$(\mathrm{g})$

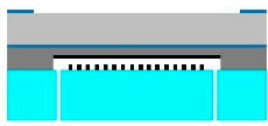

(i)

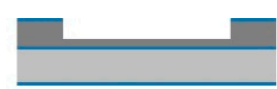

(c)

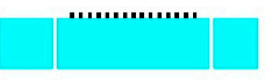

(h)

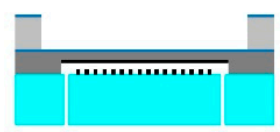

(k)

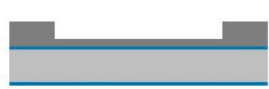

(d)

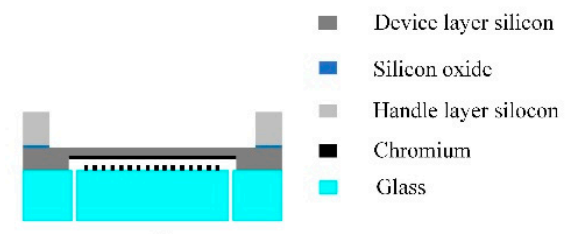

(1)

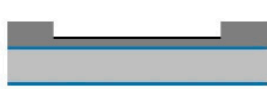

(e)

Figure 2. Micro-Electro-Mechanical System (MEMS) process of the acoustic sensor chip.

(a) Silicon oxide films $500 \mathrm{~nm}$ in thickness were deposited on both surfaces of the SOI substrate by thermal oxidation.

(b) On the device layer, the silicon oxide film in the cavity area was etched by reactive ion etching (RIE).

(c) With the silicon oxide film as the mask, silicon in the device layer was etched by the wet method for the cavity.

(d) The remaining silicon oxide film on the device layer was removed by RIE.

(e) A $50 \mathrm{~nm}$ chromium film for the reflective layer was sputtered on the device layer and patterned.

(f) A $50 \mathrm{~nm}$ chromium film for the grating was sputtered on the glass substrate.

(g) The chromium film was patterned by ion beam etching (IBE).

(h) Through holes were made in the glass substrate by laser cutting.

(i) The two wafers were assembled by anodic bonding.

(j) On the handle layer of the SOI substrate, the silicon oxide film in the diaphragm area was etched by RIE.

(k) The silicon of the handle layer in the diaphragm area was etched by deep reactive ion etching (DRIE) until it reached the buried oxide layer.

(l) The exposed silicon oxide film was etched by RIE.

As shown in Figure 3a, unlike the conventional process to fabricate a silicon diaphragm on an SOI substrate, an approximately $17 \mu \mathrm{m}$ deep cavity was made in the $20 \mu \mathrm{m}$ thick device layer and the remaining silicon in the device layer was for the diaphragm. Figure $3 \mathrm{~b}$ shows that the $2.4 \mu \mathrm{m}$ period grating in the sensor was fabricated with high precision. At last, the bonded wafer was divided into sensor chips with $10 \mathrm{~mm}$ diameter, as Figure 3c shows.

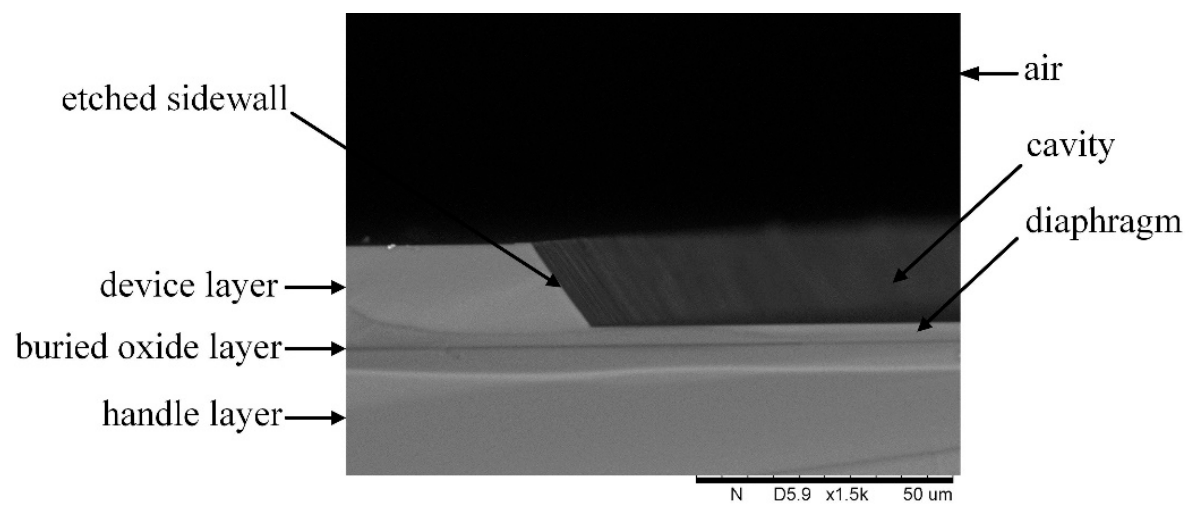

(a)

Figure 3. Cont. 


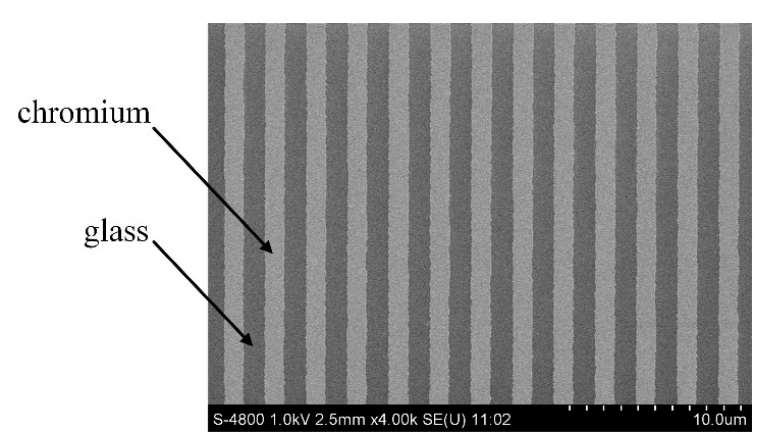

(b)

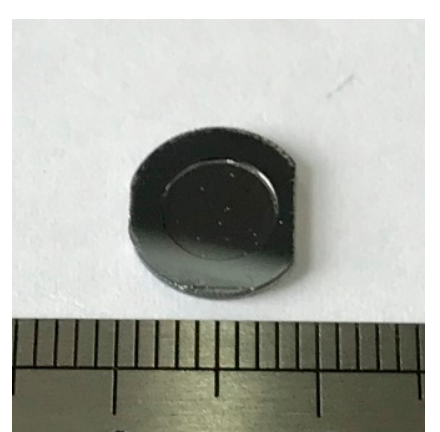

(c)

Figure 3. Photographs of the fabricated samples: (a) the etched cavity; (b) the micro grating; (c) the sensor chip.

\subsection{The Methods}

The interference spectrum of the interference cavity was measured using an optical spectrum analyzer (YOKOGAWA, AQ6379B). Acoustic signals in the test of the sensor's performance were generated from a speaker driven by a waveform generator (Agilent, 33500B). The output voltage signal from the sensor was detected by a mixed signal oscilloscope (Keysight, MSO-X 2024A). The frequency characteristic of the fabricated sensor was investigated by an acoustic sensor calibration system consisting of an input/output generator module (B\&k, 3160-A-042), a phase calibrator (GRAS, 51AB), a calibration microphone (B\&k, 4193-L-004), and measurement software (B\&K, PULSE LabShop). In the stability test, the environmental temperature was controlled using a temperature and humidity test chamber.

\section{Results and Discussion}

\subsection{The MEMS Sensor Chip}

The interference cavity length of the fabricated sensor chip was measured from its interference spectrum with broadband incident light, as Figure 4 shows. The cavity length is calculated as $16.919 \mu \mathrm{m}$. There was a small error between the fabricated cavity length and the designed one. As shown in the interference spectrum, the wavelength difference between the wave crest and the wave trough around $650 \mathrm{~nm}$ is $7 \mathrm{~nm}$. It is indicated that the short-cavity structure is not quite sensitive to the wavelength of the laser. Given the problem that the laser diode is sensitive to variations in the environment, the short-cavity design is beneficial to improving the stability. In addition, calculated using Equation (2), the temperature coefficient of the cavity length is $0.0423 \mathrm{~nm} /{ }^{\circ} \mathrm{C}$. With a $650 \mathrm{~nm}$ laser source, the coefficient of the phase difference is $0.047^{\circ} /{ }^{\circ} \mathrm{C}$. The temperature coefficient of the short cavity is so low that it is hardly affected by the environmental temperature.

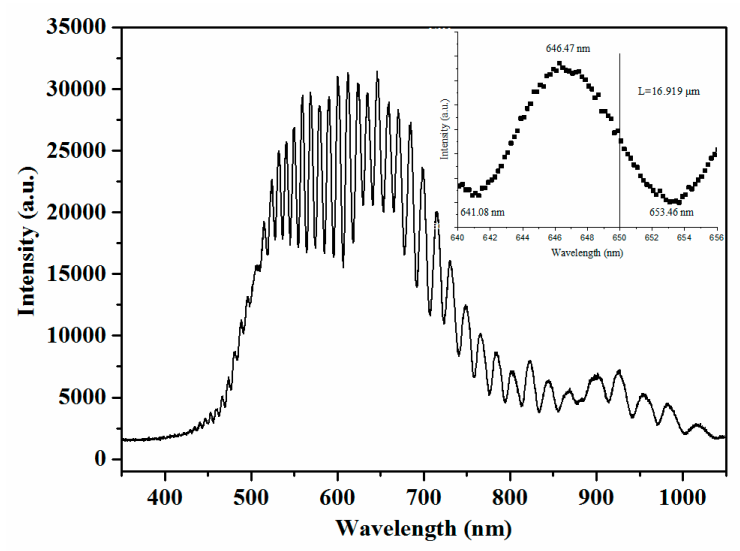

Figure 4. Interference spectrum measured for determining the cavity length. 


\subsection{Response to Acoustic Signal}

The packaging structure of the acoustic sensor designed based on the optical interference principle is shown in Figure 5. The MEMS sensor chip was packaged on the top of the housing and the diaphragm was exposed in order to sense acoustic signals. For the light path, the height from the surface of the photodetector to the surface of the grating $(h)$ and the distance between the center of the laser diode and the center of the photodetector $(d)$ are decided by the angle of the grating's first diffraction order $(\theta)$. This means that the height of the packaged sensor is mainly limited by the period of the grating, as enough space is needed for the optical devices. Both the housing and the optical devices were installed on the PCB with a conditioning circuit for acoustic detection. The circuit consisted of the drive part connected with the laser diode, the signal process part connected with the photodetector, and the filter part. Then, the output voltage signal from the circuit was used to detect acoustic signals.

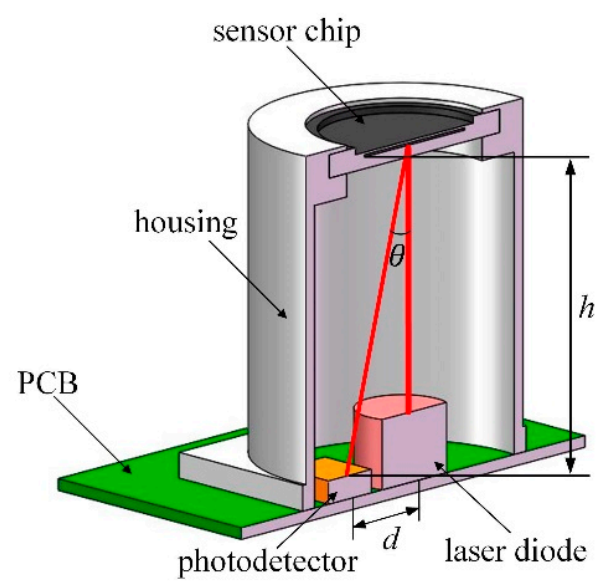

Figure 5. Schematic diagram of the packaged acoustic sensor.

The response of the sensor to an acoustic signal of $1 \mathrm{kHz}$ frequency is shown in Figure 6. The waveform of the output voltage signal and its Fast Fourier Transformation (FFT) indicate that the output of the sensor for acoustic detection is of high quality. With calibration by the standard microphone, the output values of the sensor under different acoustic pressures are shown in Figure 6c. For acoustic pressure lower than $13 \mathrm{~Pa}$, the response is linear and the sensitivity is $-15.14 \mathrm{~dB}$ re $1 \mathrm{~V} / \mathrm{Pa}$, according to the linear fit with a $0.99635 \mathrm{R}^{2}$ value. When the pressure becomes higher, the response increases.

The frequency characteristic of the fabricated sensor was investigated by the acoustic sensor calibration system described in Section 2.3. When the system was operated, the generator drove the calibrator to provide a sweep acoustic signal. Then, the outputs of the sensor and the calibration microphone were imported into the input/output module and processed by the software. In the measurement software, the output of the sensor for every frequency was compared with that of the calibration microphone. Then, the difference between them was calculated; these differences are shown in Figure 7. The sensitivity of the calibration microphone is $-37.8 \mathrm{~dB}$ re $1 \mathrm{~V} / \mathrm{Pa}$ and the flatness of its frequency response was $\pm 1 \mathrm{~dB}$ from $0.12 \mathrm{~Hz}$ to $7 \mathrm{kHz}$ for the pressure field, according to its specifications. Defining the response of the calibration microphone as stable, the difference between the highest sensitivity and the lowest one of the fabricated sensor is $10 \mathrm{~dB}$ within the frequency range from $100 \mathrm{~Hz}$ to $2.5 \mathrm{kHz}$. 


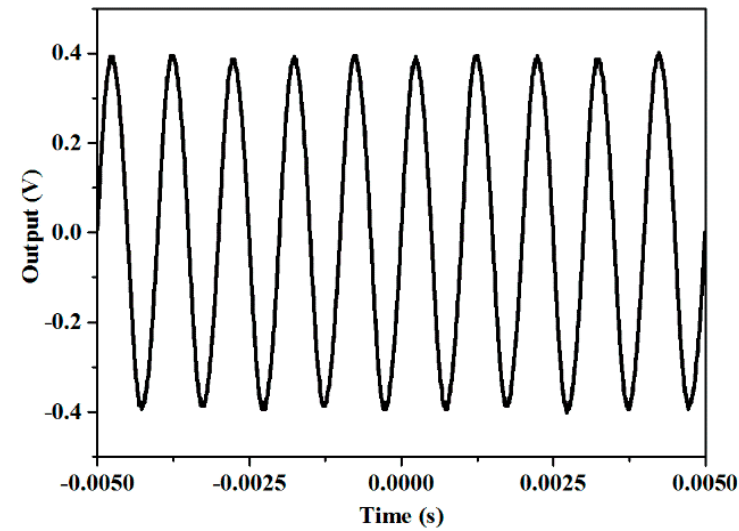

(a)

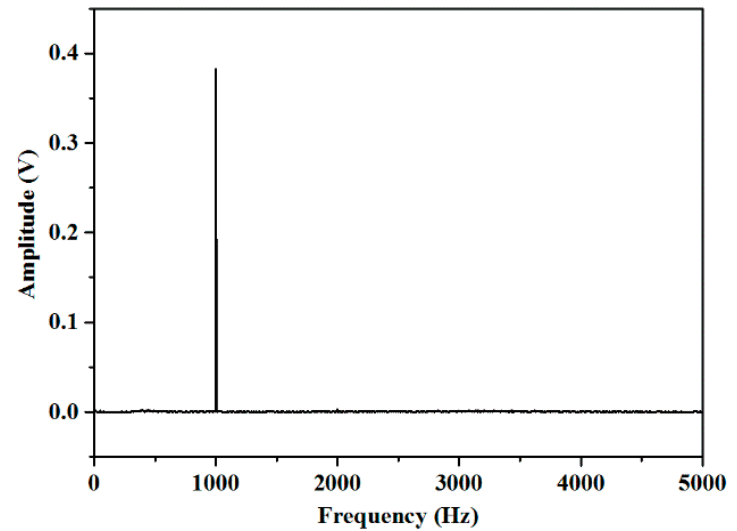

(b)

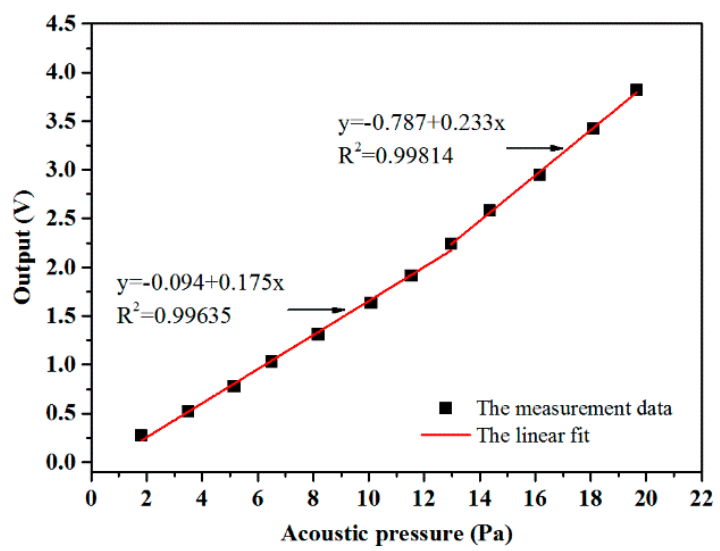

(c)

Figure 6. Response of the sensor measured with an acoustic signal of $1 \mathrm{kHz}$ frequency: (a) time domain signal; (b) FFT of the time domain signal; (c) the relationship between the acoustic pressure and the sensor's output.

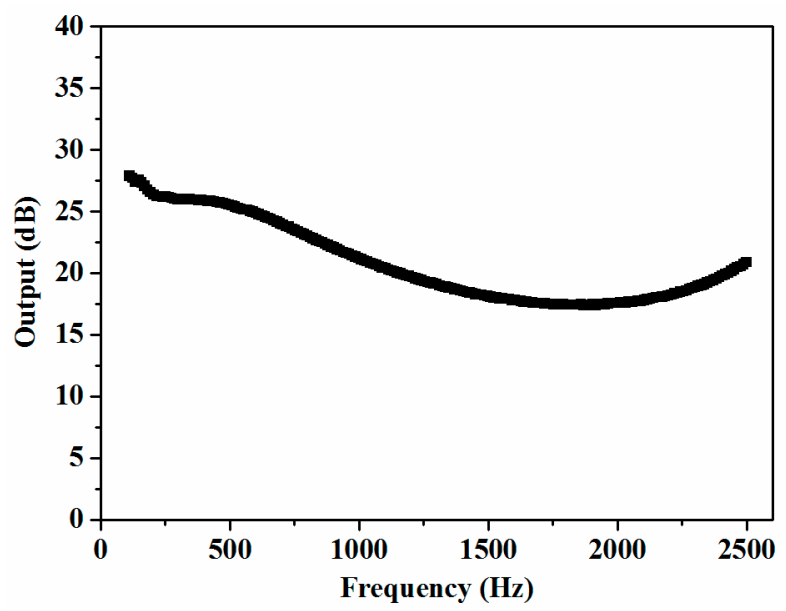

Figure 7. Frequency response of the fabricated sensor compared with that of the calibration microphone.

\subsection{Stability of the Sensor}

The stability of the acoustic sensor against environment temperature variations was tested in the temperature and humidity test chamber. There was no additional design of the sensor chip or the circuit for freezing, so the sensor was not operated under $0{ }^{\circ} \mathrm{C}$. Further, the operating temperature ranges of the laser diode $\left(-36{ }^{\circ} \mathrm{C}\right.$ to $\left.65^{\circ} \mathrm{C}\right)$ and the photodetector $\left(-25^{\circ} \mathrm{C}\right.$ to $\left.85{ }^{\circ} \mathrm{C}\right)$ in the sensor 
system limited the highest operating temperature. In the test, the environment temperature was controlled from $5{ }^{\circ} \mathrm{C}$ to $55^{\circ} \mathrm{C}$. The measured peak-to-peak values of the sensor's response to the fixed acoustic signal are shown in Figure 8. The mean of the values is $1.065 \mathrm{~V}$, and the changes are within $0.049 \mathrm{~V}$, meaning $4.6 \%$, when the temperature varied by $50{ }^{\circ} \mathrm{C}$.It is indicated that the acoustic sensor with a designed short-cavity structure achieved high thermal stability.

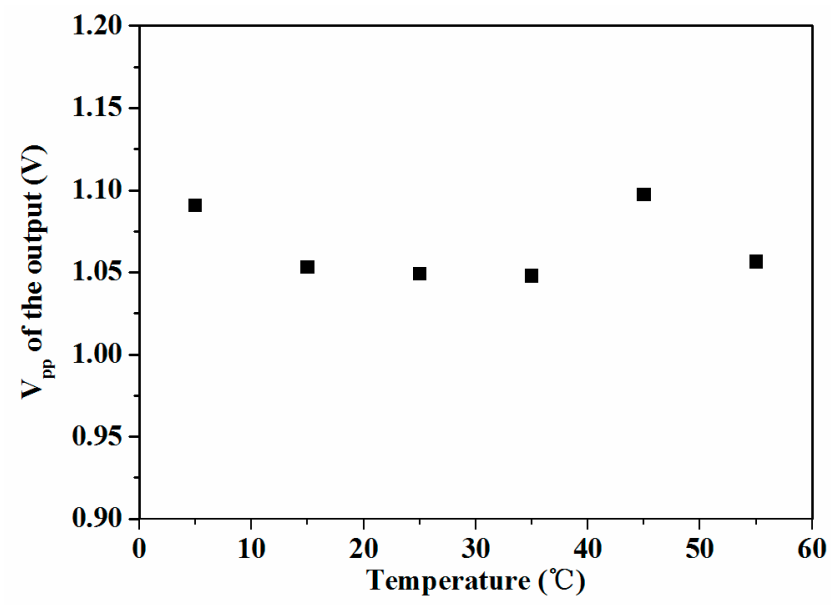

Figure 8. Response of the fabricated sensor with varying temperature.

\section{Conclusions}

In this work, an optical MEMS acoustic sensor based on grating interferometer was designed and fabricated. The structure of the sensor chip was optimized to enhance the acoustic detection sensitivity, and a short-cavity structure was designed to improve the stability against environment temperature variations. The MEMS process was developed to fabricate the sensor chip with a short-cavity design. The fabricated sensor chip was packaged with optical devices and a conditioning circuit for acoustic detection. The output voltage signal of the sensor is of high quality. The sensitivity of the acoustic sensor is up to $-15.14 \mathrm{~dB}$ re $1 \mathrm{~V} / \mathrm{Pa} @ 1 \mathrm{kHz}$, and the variation of the sensitivity is within $10 \mathrm{~dB}$ in the frequency range from $100 \mathrm{~Hz}$ to $2.5 \mathrm{kHz}$. The temperature coefficient of the short-cavity interferometer is very low, offering the sensor high thermal stability. The output signal of the developed acoustic sensor almost unchanged as the environment temperature varied from $5{ }^{\circ} \mathrm{C}$ to $55^{\circ} \mathrm{C}$.

Author Contributions: Conceptualization, Z.-M.Q.; Investigation, M.Z., G.W. and D.R.; Methodology, M.Z. and R.G.; Resources, Z.-M.Q.; Supervision, Z.-M.Q. and X.L.; Writing-original draft, M.Z.; Writing-review and editing, M.Z., Z.-M.Q. and X.L.

Funding: This research was funded by National Natural Science Foundation of China, grant numbers 61801456, 61601436, and 61501425; Natural Science Foundation of Beijing Municipal, grant number 4174108; and China Postdoctoral Science Foundation, grant number 2018M641472.

Acknowledgments: We thank the members of the clean room from the State Key Laboratory of Transducer Technology for their assistance with the MEMS processes in the manuscript. We are grateful to Fei Xiong for the etching and Jian-gang Zhang for the sputtering.

Conflicts of Interest: The authors declare no conflict of interest.

\section{References}

1. Fu, T.; Wei, P.; Han, X.L.; Liu, Q.B. Application of fiber Bragg grating acoustic emission sensors in thin polymer-bonded explosives. Sensors 2018, 18, 3778. [CrossRef] [PubMed]

2. Lyu, C.; Wu, C.; Tam, H.Y.; Lu, C.; Ma, J.G. Polarimetric heterodyning fiber laser sensor for directional acoustic signal measurement. Opt. Express 2013, 21, 018273. [CrossRef] [PubMed]

3. Xu, F.; Shi, J.H.; Gong, K.; Li, H.F.; Hui, R.Q.; Yu, B.L. Fiber-optic acoustic pressure sensor based on large-area nanolayer silver diaghragm. Opt. Lett. 2014, 39, 2838-2840. [CrossRef] 
4. Islam, M.R.; Ali, M.M.; Lai, M.H. Chronology of Fabry-Perot interferometer fiber-optic sensors and their applications: A review. Sensors 2014, 14, 7451-7488. [CrossRef]

5. Yu, C.B.; Wu, Y.; Wu, F.; Li, C.; Zhou, J.H.; Rao, Y.J.; Chen, Y.F. Highly sensitive fiber-optic Fabry-Perot geophone with graphene-coated PMMA membrane. In Proceedings of the 25th International Conference on Optical Fiber Sensors, Jeju Island, Korea, 24-28 April 2017.

6. Liu, B.; Lin, J.; Liu, H.; Ma, Y.; Yan, L.; Jin, P. Diaphragm based long cavity Fabry-Perot fiber acoustic sensor using phase generated carrier. Opt. Commun. 2017, 382, 514-518. [CrossRef]

7. Lan, C.M.; Zhou, W.S.; Xie, Y.W. Detection of ultrasonic stress waves in structures using 3D shaped optic fiber based on a Mach-Zehnder interferometer. Sensors 2018, 18, 1218. [CrossRef]

8. Wei, P.; Han, X.L.; Xia, D.; Liu, T.L.; Lang, H. Novel fiber-optic ring acoustic emission sensor. Sensors 2018, 18, 215.

9. Chen, Q.M.; Jin, C.; Bao, Y.; Li, Z.H.; Li, J.Q.; Lu, C.; Yang, L.; Li, G.F. A distributed fiber vibration sensor utilizing dispersion induced walk-off effect in a unidirectional Mach-Zehnder interferometer. Opt. Express 2014, 22, 2167-2173. [CrossRef]

10. Ma, J.; Yu, Y.Q.; Jin, W. Demodulation of diaphragm based acoustic sensor using Sagnac interferometer with stable phase bias. Opt. Express 2015, 23, 29268-29278. [CrossRef] [PubMed]

11. Jo, W.; Akkaya, O.C.; Solgaard, O.; Digonnet, M.J.F. Miniature fiber acoustic sensors using a photonic-crystal membrane. Opt. Fiber Technol. 2013, 19, 785-792. [CrossRef]

12. Liu, H.J.; Currano, L.; Gee, D.; Helms, T.; Yu, M. Understanding and mimicking the dual optimality of the fly ear. Sci. Rep. 2013, 3, 2489. [CrossRef]

13. Liu, B.; Lin, J.; Liu, H.; Jin, A.; Jin, P. Extrinsic Fabry-Perot fiber acoustic pressure sensor based on large-area silver diaphragm. Microelectron. Eng. 2016, 166, 50-54. [CrossRef]

14. Wang, W.H.; Wu, N.; Tian, Y.; Wang, X.W.; Niezrecki, C.; Chen, J.L. Optical pressure/acoustic sensor with precise Fabry-Perot cavity length control using angle polished fiber. Opt. Express 2009, 17, 16613-16618. [CrossRef]

15. Wang, X.; Feng, L.H.; Yao, B.Y.; Ren, X.Y. Sensitivity improvement of grating accelerometer based on differential detection method. Appl. Opt. 2013, 52, 4091-4096. [CrossRef]

16. Kuntzman, M.L.; Garcia, C.T.; Onaran, A.G.; Avenson, B.; Kirk, K.D.; Hall, N.A. Performance and Modeling of a Fully Packaged Micromachined Optical Microphone. J. Microelectromech. Syst. 2011, 20, 828-833. [CrossRef]

17. Giannopoulos, A.V.; Choquette, K.D. Position Sensing using Integrated VCSEL and PIN Photodectors. In Proceedings of the 21st Annual Meeting of the IEEE Lasers and Electro-Optics Society, Acapulco, Mexico, 9-13 November 2008; pp. 257-258.

18. Williams, R.P.; Hord, S.K.; Hall, N.A. Optically read displacement detection using phase-modulated diffraction gratings with reduced zeroth-order reflections. Appl. Phys. Lett. 2017, 110, 151104. [CrossRef]

19. Zhao, S.S.; Zhang, J.; Hou, C.L.; Bai, J.; Yang, G.G. Optical accelerometer based on grating interferometer with phase modulation technique. Appl. Opt. 2012, 51, 7005-7010. [CrossRef] [PubMed]

20. Mao, X.F.; Yuan, S.Z.; Zheng, P.C.; Wang, X.F. Stabilized fiber-optic Fabry-Perot acoustic sensor based on improved wavelength tuning technique. J. Lightwave Technol. 2017, 35, 2311-2314. [CrossRef]

21. Liao, H.; Lu, P.; Liu, L.; Wang, S.; Ni, W.J.; Fu, X.; Liu, D.M.; Zhang, J.S. Phase demodulation of short-cavity Fabry-Perot interferometric acoustic sensors with two wavelengths. IEEE Photonics J. 2017, 9, 7102207. [CrossRef]

22. Akkaya, O.C.; Kilic, O.; Digonnet, M.J.F.; Kino, G.S.; Solgaard, O. Modeling and Demonstration of Thermally Stable High-Sensitivity Reproducible Acoustic Sensors. J. Microelectromech. Syst. 2012, 21, 1347-1356. [CrossRef]

23. Cheng, J.; Zhou, Y.; Zou, X.P. Fabry-Perot cavity sensing probe with high thermal stability for an acoustic sensor by structure compensation. Sensors 2018, 18, 3393. [CrossRef] [PubMed]

24. Jo, W.; Kilic, O.; Digonnet, M.J.F. Highly sensitive Phase-Front-Modulation fiber acoustic sensor. J. Lightwave Technol. 2015, 33, 4377-4383. [CrossRef]

(C) 2019 by the authors. Licensee MDPI, Basel, Switzerland. This article is an open access article distributed under the terms and conditions of the Creative Commons Attribution (CC BY) license (http://creativecommons.org/licenses/by/4.0/). 